\title{
DESIGN OF AN OPEN CHANNEL FLUID FLOW SYSTEM FOR PIEZOELECTRIC ENERGY HARVESTING
}

\author{
Jyoti Yadav(Ph.D. Scholar) ${ }^{1} \&$ Dinesh(M. Tech. Scholar $)^{2}$
}

Abstract-This paper includes development of the model for piezoelectric energy harvesting system using hydro-dynamism and conversion of the dynamic pressure of water into electrical energy. In this article, a model has been designed to harvest energy by using dynamic pressure of water on a single patch of PVDF (Polyvinylidene fluoride), a piezoelectric material. The flowing water is made to strike on a piezoelectric patch of PVDF for the conversion of kinetic/pressure energy of water into electric potential on the basis of piezo-electric effect.

Keywords: Energy Harvesting, Piezoelectric Patch, Energy Generation, Voltage Doubler circuit, Full-bridge rectifier circuit.

\section{INTRODUCTION}

Harnessing of energy is the operation of extracting ambient energy from the environment, storing and converting it to a usable form. It is an easy way to generate electricity from the energy which is lost or unused. With the advancement in wireless and portable engineering, energy harvesting is highlighted as the alternatives of the conventional battery. Ultralow power portable electronics and wireless sensors use the conventional batteries as their power sources, but due to short and limited life than that of the device their use is somewhere restricted. Therefore, a set of researches have been done to harvest energy and apply it as a self-power source of portable devices or wireless sensors. The micro energy harvesting technology is capable of producing $\mathrm{mW}$ or $\mu \mathrm{W}$ level power. Piezoelectric materials have capability to produce electric power when stressed. This attribute makes them attractive for energy harvesting from ambient vibrations. The vibration sources can be a machine, human movement, wind, rainfall, waves, etc. The research motivation in this field is due to the reduced power requirement of small electronic components. The ultimate goal in this research field is to power such small electronic devices by using the vibrational energy available in their environment. If this can be achieved, the requirement of an external power source as well as the maintenance costs for periodic battery replacement and the chemical waste of conventional batteries can be reduced. In this paper, a model is presented for harnessing of energy using piezoelectric material with fluid flow dynamism.

\subsection{Material Selection}

In the present study, PVDF (poly-vinylidene fluoride) is used for the purpose of energy harvesting from the dynamic flow of water. As PVDF is highly flexible so it can work against high pressure and forces applied by water, light in weight, high heat resistance, low thermal conductivity, high chemical resistance, good toughness and unaffected by long-time exposure to ultra violet radiations. Because of all these reasons we have used PVDF for the selected purpose. Figure 1 shows the piezoelectric material used for energy harvesting.

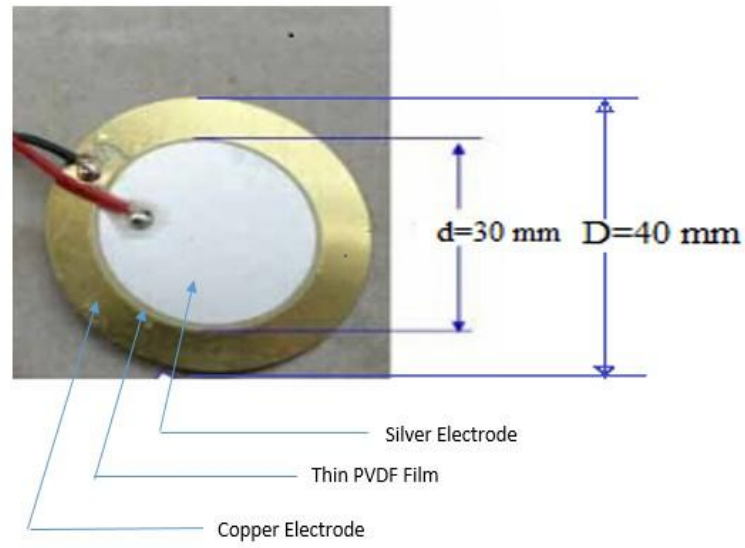

Figure 1 PVDF Piezo-Patch

\footnotetext{
${ }^{1}$ Department of Physics, Indira Gandhi University, Meerpur, Rewari, Haryana, India

${ }^{2}$ Department of Mechanical Engineering, University Institute of Engineering and Technology, Maharshi Dayanand University, Rohtak, Haryana, India
} 
Table 1 shows the basic properties of the PVDF piezo-patch used for energy production.

\begin{tabular}{|l|l|l|l|}
\hline PROPERTY & VALUE & UNITS & TEST METHOD \\
\hline Specific gravity & 1.78 & - & ASTM D 792 \\
\hline Water Absorption in 24 hours & 0.03 & $\%$ & ASTM D 570 \\
\hline Water Absorption Saturation & 0.05 & $\%$ & ASTM D 570 \\
\hline Flammability & V 0 & - & UL 94 \\
\hline Tensile Strength & 7,000 & Psi & ASTM D 638 \\
\hline Elongation & 100 & $\%$ & ASTM D 638 \\
\hline Modulus & 250,000 & Psi & ASTM D 638 \\
\hline Rockwell Hardness & $\mathrm{M} 75$ & - & ASTM D 785 \\
\hline Coefficient of Linear Thermal Expansion & $6.60^{*} 10^{-5}$ & in $/ \mathrm{in} /{ }^{\circ} \mathrm{F}$ & ASTM D 696 \\
\hline Dielectric Strength & 1600 & $\mathrm{~V} / \mathrm{m}$ & ASTM D 149 \\
\hline Volume Resistivity & $10^{14}$ & Ohm-cm & ASTM D 257 \\
\hline Dielectric Constant & 8.5 & - & ASTM D 150 \\
\hline
\end{tabular}

Table 1: Properties of PVDF material used

\subsection{Description Of Smart Electrical Circuit}

Voltage Doubler Circuit: This is an electronic circuit which charges capacitors from the input voltage and works in such a way that exactly double voltage is produced in the output. The simplest voltage doubler circuits are rectifiers which converts input AC voltage into doubled DC output voltage. The circuit components are two capacitors, two diodes and a multi-meter to measure the output. In the applications where high power is required for a high resistance load this circuit is quite beneficial. Figure 2 shows the schematic diagram and actual setup of voltage doubler circuit.

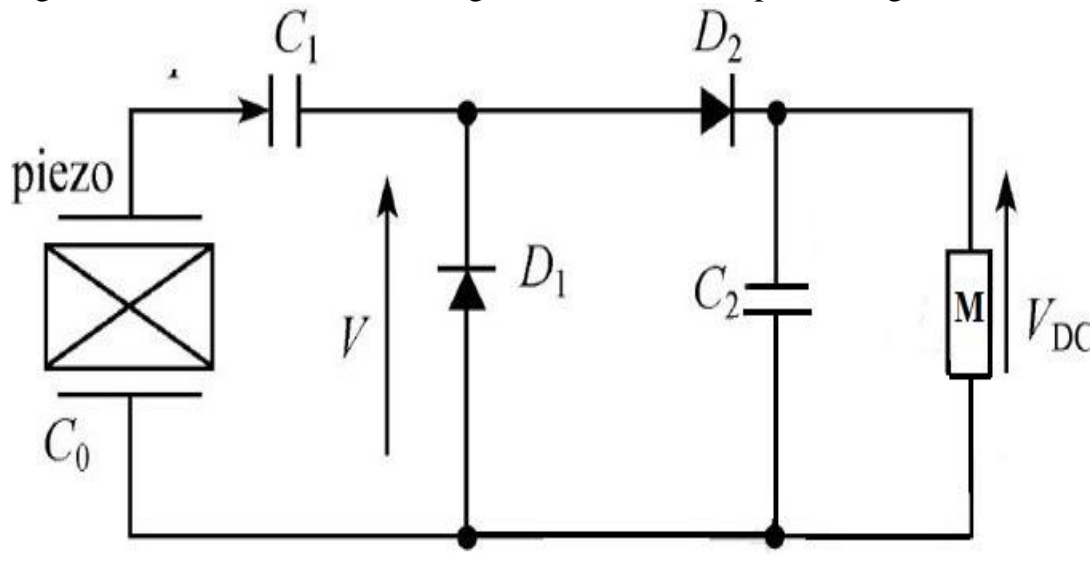

(a)

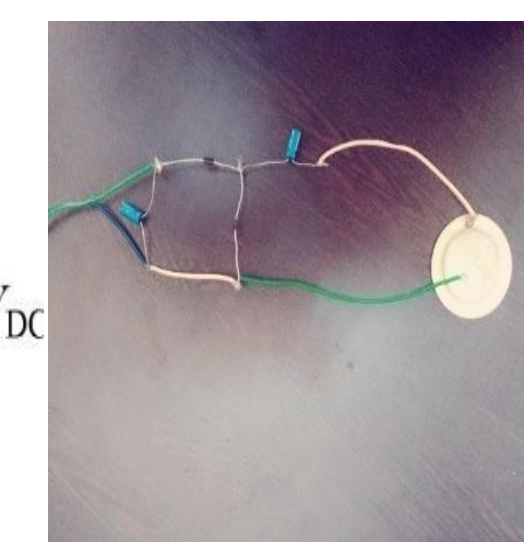

(b)

Figure 2 (A) Schematic Diagram Of Voltage Doubler Circuit (B) Actual Circuit Of Voltage Doubler Circuit 
Full Bridge Rectifier Circuit: This converts the complete AC input waveform into constant polarity DC and gives a higher average output voltage. The circuit components are two diodes and a center tapped transformer, or four diodes in bridge configuration and an AC source. Figure 3 shows the schematic diagram and actual setup of full bridge rectifier circuit.

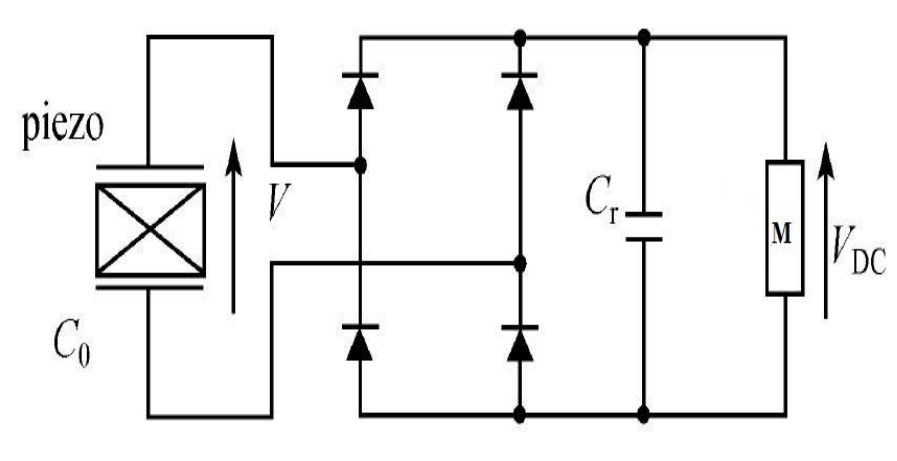

(a)

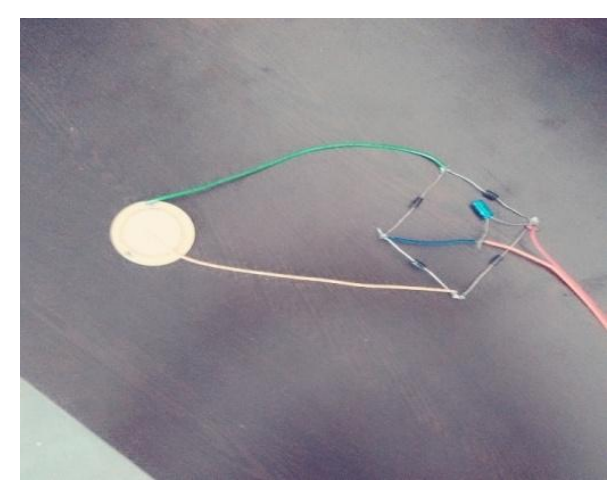

(b)

Figure 3 (A) Schematic Diagram Of Full Bridge Rectifier Circuit (B) Actual Circuit Of Full Bridge Rectifier Circuit

Figure 4 shows the component used and four different configurations of piezoelectric patch and voltage doubler circuit which are used to harvest energy from hydraulic dynamism.

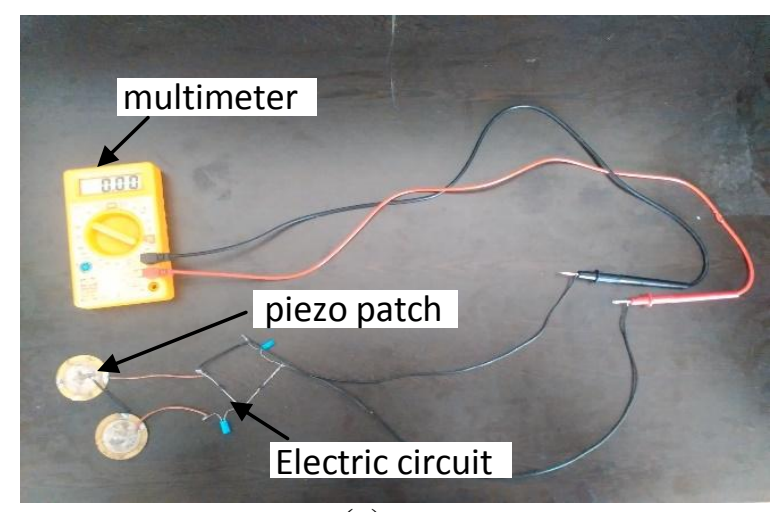

(a)

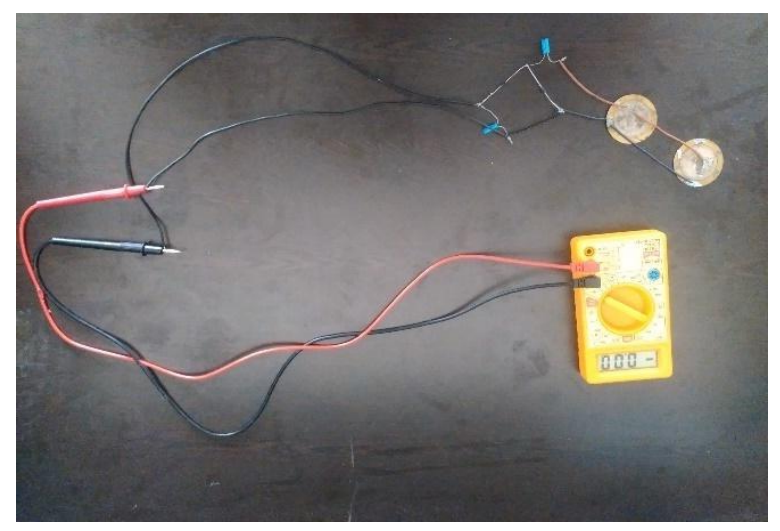

(c)

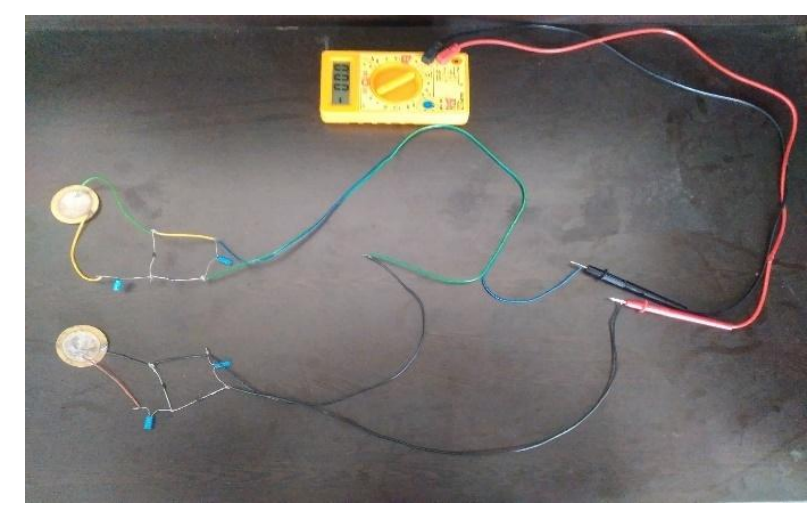

(b)

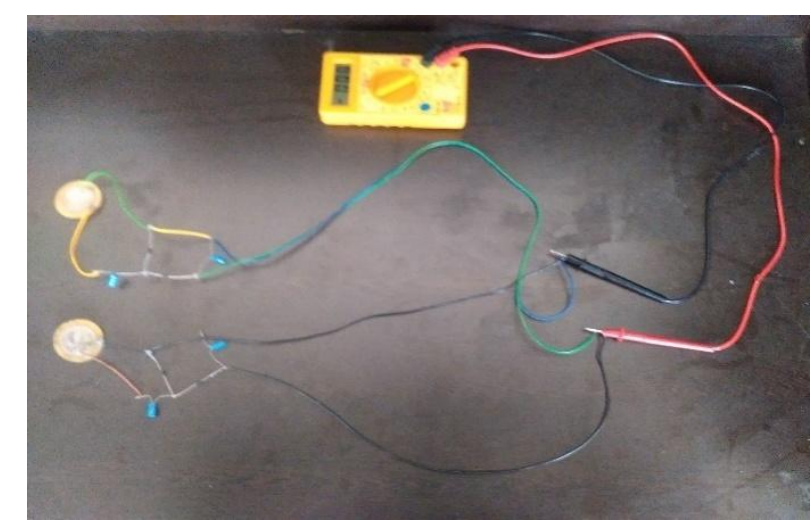

(d)

Figure 4 (A) Series Connection Of Two Piezo Patches (B) Series Connection Of Two Circuits (C) Parallel Connection Of Two

\subsection{Description Of The Model:}

Piezo Patches (D) Parallel Connection Of Two Circuits

The proposed mechanical model is composed of a water tank, a set of nozzle to increase the velocity of fluid, pipe to circulate the water flow, PVDF patches mounted on a plate and voltage doubler circuit to generate output terminal voltage. The model can be used where the water supply is continuous such as river, lakes, bridges, waterfall, etc. In case, if water is present in limited quantity then a reservoir tank can be used to store the water and a pump can be used for recirculation of the water. 
Figure 5 shows the schematic diagram and working model of energy harvesting system and figure 6 shows the components of energy harvesting system like diode, set of nozzles, capacitor etc.

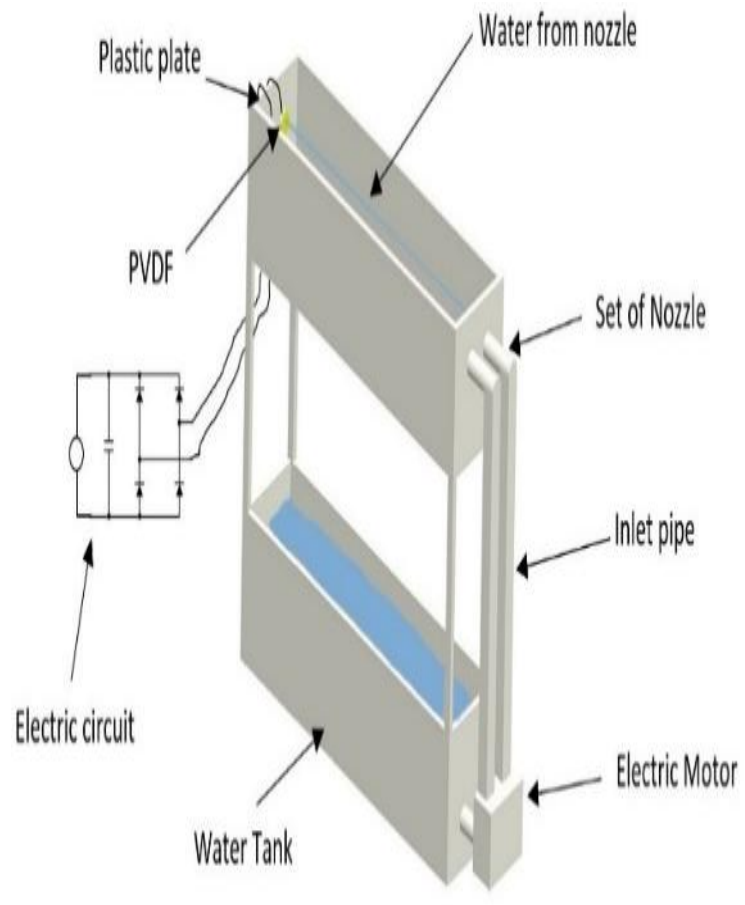

(a)

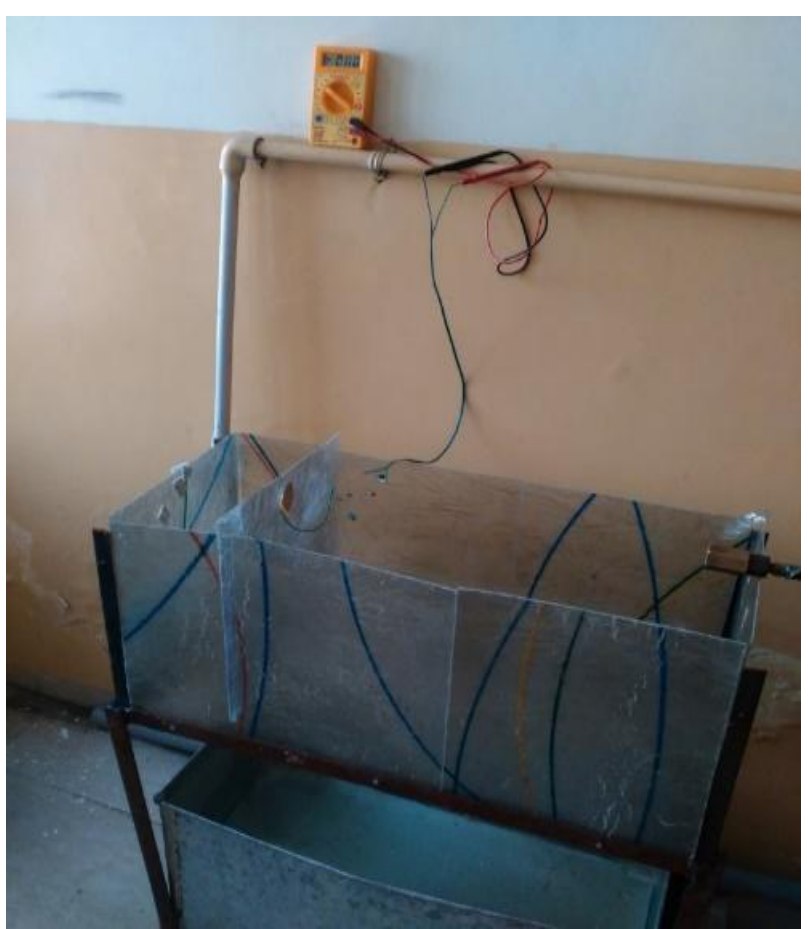

(b)

Figure: 5 (A) Schematic Diagram, (B) Experimental Model Of Apparatus
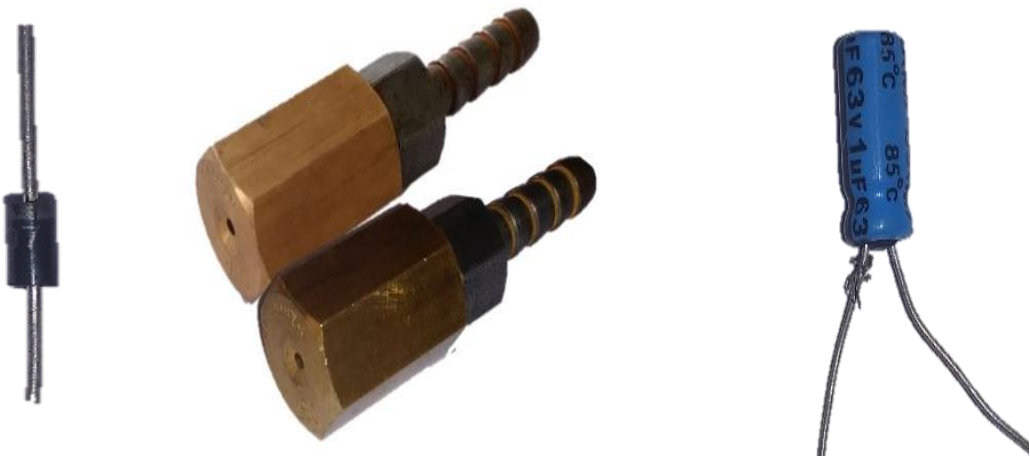

Figure: 6 Components Of Energy Harvesting System

Here, the water tank is used to store as well as supply the water. An electric motor is used to recirculate the water. Piezoelectric patch is mounted on a perforated sheet and is allowed to place in flowing water. The flowing water strikes on the piezo-patch which directly converts the vibration energy of flowing water into electrical energy on the basis of piezoelectric effect. The electric circuit is used to store the extracted energy.

\section{DISCUSSION}

Every bit we have seen different methods of energy conversion which can be utilized to harvest energy from ambient vibrations. Every method has both advantages and disadvantages together and also their use is limited to a particular case of ambient condition. The solar system is applicable only for converting energy coming from the Sun into a useable form of energy. In electromagnetic system the coil arrangement is comparatively sound and makes it hard to move quickly, which results in the difficult operation to generate a high frequency response. Electrostatic system requires some initial voltage to excite the system. Among all of these we can see that piezoelectric energy generation is quite beneficial than others as it is more reliable than other system and can be applied under wide range of excitation. Also the power requirement for initiation is very low or negligible as compared to others and piezoelectric materials can be easily integrated with other systems. Thus we see that piezoelectric materials can be used effectively to harvest energy as compared to other harvesting systems. Also 
piezoelectric materials have a large no of applications, though power output is low but can be increased by using suitable parameters. So, purpose of the paper is to present a piezoelectric energy harvesting model using PVDF-piezo material with hydro dynamism to extract maximum energy.

\section{CONCLUSIONS}

1. An effective and efficient model has been developed for piezoelectric energy harvesting using hydro-dynamism to convert the dynamic pressure of water into electrical energy.

2. The generated output can be controlled upto $12 \mathrm{~V}$ by using IC-7804 for battery charging purpose.

3. This is a cost effective and environment friendly model.

4. This system can be incorporated at the end of the flaps of boats to provide electric energy to power small devices like mobile, bulb etc.

5. The model presented here can be used to generate power from the water, which is wasted from homes, industries, power plants etc.

6. The model can be used near canal to supply electricity to the street lights.

7. The model can likewise be used where water quantity is fixed and the water recirculation is done by utilizing a water pump.

\section{REFERENCES}

[1] Adhikari, S., Friswell, M. I., \& Inman, D. J. (2009). Piezoelectric energy harvesting from broadband random vibrations. Smart Materials and Structures, 18(11), 115005.

[2] Ahmadi, M., Zhang, H. F., \& Tian, J. (2014). Investigation of Piezoelectric Energy Harvesting at Elevated Temperatures. Ferroelectrics, 460(1), 138148 .

[3] Akaydin, H. D. (2012). Piezoelectric Energy Harvesting From Fluid Flow. CITY UNIVERSITY OF NEW YORK.

[4] Akaydin, H. D., Elvin, N., \&Andreopoulos, Y. (2010). Energy harvesting from highly unsteady fluid flows using piezoelectric materials. Journal of Intelligent Material Systems and Structures, 21(13), 1263-1278.

[5] Akcabay, D. T., \& Young, Y. L. (2012). Hydroelastic response and energy harvesting potential of flexible piezoelectric beams in viscous flow. Physics of Fluids (1994-present), 24(5), 054106.

[6] Ali, W. G., \&Nagib, G. (2012, October). Design considerations for piezoelectric energy harvesting systems. In Engineering and Technology (ICET), 2012 International Conference on (pp. 1-6). IEEE.

[7] Anton, S. R., \& Sodano, H. A. (2007). A review of power harvesting using piezoelectric materials (2003-2006). Smart materials and Structures, 16(3), R1.

[8] Aridogan, U., Basdogan, I., \&Erturk, A. (2014). Multiple patch-based broadband piezoelectric energy harvesting on plate-based structures. Journal of Intelligent Material Systems and Structures, 25(14), 1664-1680.

[9] Baek, K. H., Hong, S. K., Kim, S. B., Kim, J. H., \& Sung, T. H. (2013). Study of charging efficiency of a piezoelectric energy harv esting system using rectifier and array configuration. Ferroelectrics, 449(1), 42-51.

[10] Beeby, S. P., Tudor, M. J., \& White, N. M. (2006). Energy harvesting vibration sources for microsystems applications. Measurement science and technology, 17(12), R175.

[11] Briscoe, J., \& Dunn, S. (2014). Nanostructured Piezoelectric Energy Harvesters. Springer.

[12] Do, X. D., Jeong, C. J., Nguyen, H. H., Han, S. K., \& Lee, S. G. (2011, November). A high efficiency piezoelectric energy harvesting system. InSoC Design Conference (ISOCC), 2011 International (pp. 389-392). IEEE.

[13] Erturk, A., \& Inman, D. J. (2011). Parameter identification and optimization in piezoelectric energy harvesting: analytical relations, asymptotic analyses, and experimental validations. Proceedings of the Institution of Mechanical Engineers, Part I: Journal of Systems and Control Engineering, 225(4), 485496.

[14] Erturk, A., \& Inman, D. J. (2011). Piezoelectric energy harvesting. John Wiley \& Sons.

[15] Gu, L., \& Livermore, C. (2011). Impact-driven, frequency up-converting coupled vibration energy harvesting device for low frequency operation.Smart Materials and Structures, 20(4), 045004.

[16] Guan, M., Li, Y., \& Zhao, Y. (2015). A Novel Frequency Tunable Mechanism for Piezoelectric Energy Harvesting System. Ferroelectrics, 478(1), 96105 .

[17] Deepak Chhabra, Gian Bhushan \& Pankaj Chandna (2014, March). Multilevel optimization for the placement of piezo- actuators on plate structures for active vibration control using modified heuristic genetic algorithm. In SPIE Smart Structures and Materials+ Nondestructive Evaluation and Health Monitoring (pp. 90590J-90590J). International Society for Optics and Photonics.

[18] Deepak Chhabra, Gian Bhushan, \& Pankaj Chandna (2016). Optimal placement of piezoelectric actuators on plate structures for active vibration control via modified control matrix and singular value decomposition approach using modified heuristic genetic algorithm. Mechanics of Advanced Materials and Structures, 23 (3), 272-280.

[19] Deepak Chhabra, Kapil Narwal, Pardeep Singh (2012). Design and Analysis of Piezoelectric Smart Beam for Active Vibration Control, International Journal of Advancements in Research \& Technology, 1(1), 1-5, ISSN 2278-7763.

[20] Deepak Chhabra, Gian Bhushan, and Pankaj Chandna (2014). Optimization of Collocated/Non-collocated Sensors and Actuators along with Feedback Gain Using Hybrid Multi objective Genetic Algorithm-Artificial Neural Network, Chinese Journal of Engineering, vol. 2014, Article ID 692140, 12 pages, doi:10.1155/2014/692140.

[21] Deepak Chhabra, Pankaj Chandna, Gian Bhushan (2011). Design and Analysis of Smart Structures for Active Vibration Control using Piezo-Crystals. International Journal of Engineering and Technology, 1(3), ISSN2049-304. 
[22] Budhwar, A. and Chhabra, D. (2016). "Comparison of Energy Harvesting using Single and Double Patch PVDF with Hydraulic Dynamism." International Journal of $R \& D$ in Engineering, Science and Management, 4(1), 56-67.

[23] Kumar, A. \& Chhabra, D. (2016). Study of PEH configurations \& circuitry and techniques for improving PEH efficiency. International Journal for Scientific Research and Development, 4(3), 20198-2102.

[24] Narwal, K. \& Chhabra, D. (2012). Analysis of simple supported plate for active vibration control with piezoelectric sen sors and actuators. IOSR Journal of Mechanical and Civil Engineering, 1(1), 2278-1684.

[25] Rani, P. \& Chhabra, D. (2016). Piezoelectric Energy Harvesting from Fluid Flow Dynamism using PVDF. International Journal of R\&D in Engineering, Science and Management, 4(1), 23-36. 